\title{
The Culture of Overwork in the Discipline of Political Science
}

\section{What do you need to know about the culture of overwork?}

The culture of overwork is not a new phenomenon. Within the discipline of political science, focusing on scholarship holds out the promise of determining one's own schedule, but managing the array of tasks associated with an academic career presents an array of challenges that begin with the prospective graduate student. These challenges shapeshift throughout PhD students' experiences, suggesting that the culture of overwork does not remain static over time and shifts in accordance with progression throughout a $\mathrm{PhD}$ in political science. But what is the culture of overwork? Broadly, the culture of overwork has been encapsulated by the American Dream - although not a concept limited to the U.S., as the problem has been shown to be endemic elsewhere, such as Japan, the UK, and Australia (Walsh 2013, 151) - in which people, through hard work and determination, are believed to be able to achieve wealth and status. Thus, it is believed that the most value is attributed to those who work long hours and appear omnipresent (presenteeism) as these individuals are perceived to be the most diligent. It is also the normalization of long work hours, the erosion of personal and professional boundaries, the glamorization of always being consumed by work, and the romanticization of phrases like 'rise and grind'.

However, the culture of overwork can be characterized more specifically in the domain of political science. Here, the culture of overwork can be identified by its overlapping responsibilities for graduate students, especially those who are teaching or research assistants. In these roles, you are typically engaged in academic service (reviewing papers, presenting at conferences), university service (serving on university and graduate student committees), department service (helping your peers, administrative staff, and faculty members), funding (writing grants and fellowship applications), research (reading, writing, and submitting manuscripts to journals, undertaking fieldwork), and teaching (leading discussion sections, holding office hours, grading papers, responding to emails, advising students) (Guo 2014). In addition to all of these tasks, you may be constantly checking your emails and phone, writing policy reports, and performing community service. At different stages of your $\mathrm{PhD}$ program in political science, you can expect these obligations to change in intensity. For example, as a prospective student, you will be managing your transition into a PhD program and preparing for classes, but as a post-candidacy student, you will be focused on wrapping-up your dissertation, building a professional network, presenting at conferences, publishing research, and submitting job applications. Thus, your work will originate from multiple sources which rarely coordinate assignments and deadlines.

Given that the sources of work output are often independent, you will be left to your own devices to organize your time effectively and to balance these obligations. Expectations can seem especially burdensome when you receive critical student evaluations, teach challenging course material, have quick grading deadlines, experience journal rejections, fail to receive job offers, and more. Even while you are "acutely conscious of how little time" there is - and some mentors may assume all of your free time is available for responding to emails, reading academic literature, and working on class papers - and when peers engage in "busy-bragging" as a status symbol, rest assured there are ways to navigate the culture of overwork in academia (Robson 2021).

\section{Why does the culture of overwork matter?}

Before turning to the ways to navigate the culture of overwork, it is first important to understand why the culture of overwork matters. The culture of overwork can adversely affect your physical and mental health, which can subsequently damage your productivity. More specifically, overwork can make you susceptible to illnesses including sleeping disorders, heart problems, alcoholism, anxiety, depression, burnout, and panic attacks (Jongepier and van de Sande 2021). Burnout has been described by the World Health Organization as a syndrome "resulting from chronic 
workplace stress that has not been successfully managed," and is characterized by "feelings of exhaustion, negative feelings about a job and reduced professional efficacy" (Lufkin 2021). And while caffeine can artificially and temporarily sustain you, it cannot sufficiently counteract the lack of sleep and near-constant expenditure of mental energy, thereby exacerbating your capacity to be productive. This state of existence can lead you to being physically and emotionally exhausted and result in a loss of passion for political science, which will only further dampen your efforts to be productive.

Instead, your efforts ought to focus on producing good quality work and to recognize that you need not stay fixed on the "hedonic treadmill" in which your achievements pile up, one after the other, and become a never-ending cycle of overwork (Robson 2021). Similarly, you should avoid the "productivity trap," where you feel like you can "never truly escape the feeling that you should be doing more" (Robson 2021). Although both the hedonic treadmill and productivity trap can contribute to feeling like you are "in demand and scarce" and, therefore, important, the aforementioned physical and mental health issues associated with these efforts to be always-productive will be to your detriment (Bellezza et al. 2016, 135). But what does overwork look like in practice? How do you know when enough is enough? Everyone has their own limits, and simply because your fellow graduate student works into the evening and on their weekends does not mean that you need to do the same if you are capable of fulfilling your obligations. Long hours - usually defined as being over 45 to 55 hours per week (Entrepreneur 2017; Headlee 2020; Walsh 2013, 153) - will only lead to fatigue and sharp declines in productivity and the quality of your work.

It is also crucial to acknowledge that the culture of overwork is not new, and that the notion of sleep as a luxury and valorization of wakefulness can be traced back in time. Emerging from mounting challenges to the United States' economic supremacy in the 1970s, there was a newfound commitment for the workforce to go "all-out" to ensure the country could continue to compete on a global scale (Derickson 2013, 20). In this process, there were "potent promoters of sleep deprivation" who reinforced the idea that a workforce was capable of "constant availability, ability to function competently" and that sleep-deprivation was necessary to succeed in a "24/7/365 society" (Derickson 2013, 1, 142-143). Fast-forward to the present day and you encounter the same level of pride found in tech entrepreneurs and corporate leaders who echo traits associated with the culture of overwork. With instantaneous communication, it has become even more challenging to 'switch off'.

However, it does not have to be this way. If you have experienced burnout as a political science graduate student, use it as a platform for change. Begin by recognizing that time spent in pursuit of non-political science and non-academic endeavors are important and enriching too. Such activities - going to the theater, reading a non-academic book, going to the gym, forest-bathing, spending time with family and friends, cooking a nice meal, or whatever activities you enjoy and value - can make you a more well-rounded person as opposed to someone who is consumed by allthings-political-science. Develop a more well-rounded identity that goes beyond your job title as a Graduate Teaching or Research Assistant of Political Science. It is not wasteful to rest, and the next section will outline ways in which political science graduate students can deal with the culture of overwork.

\section{What can you do about the culture of overwork?}

Generally, all political science graduate students should avoid busy-bragging - or taking pride in being overworked. You should focus on time management to assist in organizing all your responsibilities to prevent you from feeling overwhelmed, and there are several ways to do this. If you struggle with self-motivation, you can utilize 'Study with Me' videos on platforms like YouTube, especially ones that employ Pomodoro techniques to ensure you take breaks. Pomodoro is a timed technique where, for example, you study for 20 or 50 minutes and then take a 10-minute break. The process is then repeated with a larger break in the middle. In those breaks, productivity experts 
strongly recommended that you get up and move around. Whether you are in the library, working from home, or a graduate office, you should move away from your work and study space. Another tactic is to create to-do lists that create a sense of achievement and further motivate yourself to continue working. However, be wary of adopting too many big goals. Instead, break large projects down into smaller, more manageable tasks. You must learn to prioritize and, in doing so, you can make bigger strides by focusing on fewer goals that are smaller in size. Such approaches are especially important for doctoral students who have children or other care-giving responsibilities.

In line with taking adequate breaks, ensure you are getting enough sleep - usually seven or eight hours - as well as adequate nutrition, exposure to sunlight, and exercise. While vitamin supplements and sunlight through a window can help, a healthy routine combined with regular exposure to nature is better. Do not be afraid to take a nap if you are sleep deprived or generally exhausted. Avoid screen exposure from your television and mobile phone too close to night-time, not only for the sake of the blue light negatively impacting your capacity to sleep, but to avoid reading emails that can wait until the morning. Consider putting your phone on silent/do not disturb mode. Further, if you are experiencing any mental health struggles, you should seek out your university's counselling, well-being, and therapy services. If these are not available and you have healthcare, you should assess what external services are available.

Moreover, recognize that your individual actions cannot change the culture of overwork, but nor are they without effect. The culture of overwork is endemic in many political science graduate programs, but you can cultivate habits and strategies to disengage from this culture that not only help you but normalize self-care for other graduate students. As part of this effort, if you are a Teaching Assistant, you should consider how your communication and demeanor may positively affect undergraduate students through discussion sections, grading comments, office hours, and email responses. If, however, you have other intersectional identities that result in implicit bias or undue scrutiny of your performance in graduate school, you may consider quietly implementing these worklife balance tactics, while leaving efforts to overtly challenge the norms in your graduate program to others.

For example, women in graduate school are more likely than men to believe that "graduate school and parenthood are fundamentally incompatible" because of graduate schoolwork requirements (Mason, Wolfinger and Goulden 2013, 11). Those who do become mothers face challenges in navigating the fine line posed by the culture of overwork - choosing between the total dedication expected for academia and the total devotion expected for parenthood. This difficult position is compounded by the lack of faculty mothers, the perception that universities are not "family friendly," and stereotypes that women cannot "succeed as professionals while also having a family life" (Mason, Wolfinger and Goulden 2013, 16, 18). However, it is not all bad news. Some universities are offering mothers leave for a semester and to return with penalty, as well as grants for child-raising expenses, medical plans for student parents, and on-campus child-minding facilities (Mason, Wolfinger and Goulden 2013, 23). Additionally, in resisting the binary posed by overwork culture - to be a mother or a graduate student - student mothers can shift toward "and, and, and" and to identify a balance between responsibilities (Guyonette 2018, 45).

For prospective students and first-year students who are acclimatizing to the $\mathrm{PhD}$ program in political science, you may feel burned out by your newfound responsibilities and the degree to which they differ from your previous educational experiences. This situation can seem even worse as a firstgen student and/or international student as there are new cultural and educational expectations to learn. Nonetheless, in your first year, you should identify a study space that is conducive for productivity and well-being - this may be a desk set-up in your apartment or house, a graduate office (sometimes shared), or your university's library. Additionally, you should collaborate with your peers - including students in the years above (Headlee 2020). If you are struggling with assigned literature 
in your political science program, talk to your peers to share your perspectives or what you found interesting. In doing so, you will more quickly learn to identify patterns in literature, and you can tease these out in your graduate seminars. You should also engage with your faculty adviser and mentor if you are struggling and ask for assistance or extensions if you truly need them.

For pre-candidacy students, the primary challenges are in balancing coursework with research and teaching obligations, in addition to emerging roles in applying for grants, fellowships, and conferences. By now, you will have hopefully identified a routine that works best for you in fulfilling your obligations without being overworked. If you find that your responsibilities as a Teaching or Research Assistant are taking more time than you are contracted for - typically 20 hours per week then speak with your adviser as to how to remedy this (Headlee 2020). There may be times that you do not recognize that you are overworking, especially if you are committed to your activities, but greater self-awareness can help you prevent burn out (Walsh 2013, 156). Remember how far you have come from your first year and the progress you have made. Consider what the coming years hold for you and do not lose sight of the end goal of obtaining a $\mathrm{PhD}$ in political science. If you fall off the bandwagon - receiving a low grade, missing a deadline, or being unprepared for a presentation - you can recover and get back on track. Do not forget that you have time ahead to learn from these experiences and continually improve yourself, personally and professionally.

For post-candidacy students, attempting to strike a balance between data collection, fieldwork, dissertation writing, and job searches - with all the additional academic, departmental, and university service commitments expected at this stage - can be challenging. At this point, your established routine of attending classes will change dramatically, illustrating that work-life balance is dynamic. In order to ground yourself and create a new routine, you should consider joining or starting a weekly writing accountability group. Post-candidacy can be isolating, and such a group can help keep you focused (Ali 2021). Further, consider preserving your weekends and/or evenings and avoid spending all your time at your desk now that you have greater flexibility in your schedule. Be sure that your non-academic friends and family that this phase of your academic program is particularly rigorous and that they need to respect your boundaries (Ali 2021). If new teaching or research opportunities arise - choose wisely and carefully. Declining tangential opportunities can help you maintain progress toward degree completion, as spreading yourself too thin will likely result in poor performance across all that you do. As you enter the job market, save yourself time from endlessly searching by creating job alerts for commonly used higher education websites, including

HigherEdJobs, LinkedIn, HERC Jobs, and APSA ejobs. Do not overlook your university's career and mentoring services, which can also be a valuable resource.

Finally, with all of this advice in mind, remember that you have got to where you are in your political science graduate program through your diligence and intelligence, among other skills. There may be times when you are burned out and all you can envisage is dropping-out of the program, believing you are doomed to the downward spiral that is the culture of overwork. Keep in mind that many graduate students will feel this way at some point during their graduate program. With these solutions described above in mind, you can push back and persevere, establish a healthy routine, ensure mental and physical well-being, and be productive all at once.

\section{Bibliography}

Ali, Samina G. 2021. "6 Tips for the Final Year of Your Dissertation Marathon.” Inside Higher Ed [website], October 18, 2021. https://www.insidehighered.com/advice/2021/09/21/tips-final-yearwriting-your-thesis-opinion.

Bellezza, Silvia., Neeru Paharia., and Anat Keinan. "Conspicuous Consumption of Time: When Busyness and Lack of Leisure Time Become a Status Symbol." Journal of Consumer Research 44(1): 118-138. https://doi.org/10.1093/jcr/ucw076 
Derickson, Alan. 2014. Dangerously Sleepy: Overworked Americans and The Cult of Manly Wakefulness. Philadelphia: University of Pennsylvania Press.

Entrepreneur. 2017. "How the Culture of Overwork is Damaging Your Productivity and Your Health." Entrepreneur [website], October 18, 2021. https://www.entrepreneur.com/article/298956.

Guo, Philip. 2014. "Why Academics Feel Overworked." Inside Higher Ed [website], October 18, 2021. https://www.insidehighered.com/advice/2014/12/01/essay-why-academics-feel-overworked.

Guyonette, Kelly W. 2018. “The Undecided Narratives of Becoming-Mother, Becoming-Ph.D.” In Feminism and Intersectionality in Academia: Women's Narratives and Experiences in Higher Education, eds. Stephanie Anne Shelton, Jill Ewing Flynn, Tanetha Jamay Grosland, 37-48. Cham, Switzerland: Palgrave Macmillan.

Headlee, Celeste. 2020. Do Nothing: How to Break Away from Overworking, Overdoing, and Underliving. New York: Harmony Books.

Jongepier, Fleuer., and Mathijs van de Sande. 2021. "Workaholic academics need to stop taking pride in their burnout." Times Higher Education [website], October 19, 2021.

https://www.timeshighereducation.com/opinion/workaholic-academics-need-stop-taking-pride-theirburnout.

Lufkin, Bryan. 2021. "Why do we buy into the 'cult' of overwork?" $B B C$ [website], August 9, 2021. https://www.bbc.com/worklife/article/20210507-why-we-glorify-the-cult-of-burnout-and-overwork.

Mason, Mary Anna., Nicholas H. Wolfinger., and Marc Goulden. 2013. "The Graduate School Years: New Demographics, Old Thinking." In Do Babies Matter? Gender and Family in the Ivory Tower. 825. Rutgers University Press.

Robson, David. 2021. "How to escape the 'productivity trap'.” $B B C$ [website], August 10, 2021. https://www.bbc.com/worklife/article/20210805-how-to-escape-the-productivity-trap.

Walsh, Janet. 2013. “Work-Life Balance: The End of the 'Overwork' Culture?” In Managing Human Resources: Human Resource Management in Transition, eds. Stephen Bach and Martin R. Edwards, 150-177. Hoboken, N.J.: Wiley-Blackwell. 